\title{
流下液膜式蒸発器用伝熱管における冷媒液膜流動の可視化
}

\author{
高橋 宏行○ ((株) コベルコマテリアル銅管)
}

\section{Visualization of refrigerant flow for falling film type evaporator tube}

Hiroyuki Takahashi

\section{Abstract}

This paper present the visualization of refrigerant flow for falling film type evaporator on enhanced tube. The enhanced tube on external surface has independent projections with a projection pitch of 26 fins per inch, and a circumferential segmentation pitches of 0.53 were tested. The observation of refrigerant flow was carried out at the evaporation pressure of $0.8 \mathrm{kPa}$, at the outlet chilled water temperature of $7{ }^{\circ} \mathrm{C}$, and at the refrigerant flow rate per unit length between 0.75 and $2.00 \mathrm{~kg} /(\mathrm{min} \mathrm{m})$. Refrigerant flow was also photographed the top of the tube at a frames rate of 500 frame per second using a high-speed video camera. The results of the study showed that a thin film refrigerant film formed on the grooves as the refrigerant flow rate decreased. Keywords: High-speed video, Evaporation, Refrigerant flow, Falling film, Enhanced tube

\section{1. 緒 論}

昨今地球環境の污染問題が深刻化する世の中, 省エネルギ 一化への取り組みは活発であり，その中の吸収式冷凍機は環 境に優しい泠涷機で, 世界的に注目されている. 吸収式冷涷 機は, 蒸発器, 吸収器, 再生器及ひ凝縮器の 4 つの主要熱交 換器にて構成され, その中で蒸発器は吸収器に次いで伝熱面 積及び容積が大きく，冷凍機全体の効率に大きな影響を及ぼ す. 蒸発器は, 熱交換器内に水平に配置した伝熱管表面に冷 媒を滴下または散布する流下液膜式熱交換器であり, 伝熱管 外表面に冷媒棭膜を形成して蒸発させる構造である.

昨今, 蒸発器に使用する伝熱管は, 各種新伝熱面形状が開 発され，試験評価がされてきた，その 1 例1) 2) として, 薄 肉銅管の管外表面に独立突起を多数設け伝熱管について性能 評価し, 従来のローフィンチューブと比較して, 泠媒の濡れ 広がり性が良く，性能向上することが報告されている.

一方, 流下液膜式蒸発器の液膜流動が観察された事例は少 なく, 観察対象の伝熱管は平滑管 ${ }^{3)}$ である. 一方, 小林ら ${ }^{4)}$ はVOF 解析による独立突起型伝熱管の液膜流動を予測した ことが報告されているが, 高性能伝熱管における液膜流動を 観察した報告は無いようである.

本報告では, 高橋ら ${ }^{5)} に よ り$ 報告された独立突起型伝熱 管における液膜流動を把握することを目的とし, 液膜流動に ついて, 高速度ビデオにて撮影し，考察した。

\section{2. 供試伝熱管}

供試管の形状寸法值を Table 1 に, 供試管の形状概略図, 管軸平行断面写真ならびに直角断面写真を Fig.1〜 3 に示す. 供試管 ${ }^{2}$ は, 独立突起型伝熱管で, 原管部外径 $\phi 16 \mathrm{~mm}$, 肉厚 $0.6 \mathrm{~mm}$ の低りん脱酸銅管 (JIS H $3300 \mathrm{C1201TS-1/2H)}$
Table 1 Test tube geometry

\begin{tabular}{l|l}
\hline OD of unenhanced section & $16 \mathrm{~mm}$ \\
\hline Wall thickness of unenhanced section & $0.6 \mathrm{~mm}$ \\
\hline Diameter over fins(mm) & $15.82 \mathrm{~mm}$ \\
\hline Fin height(mm) & $0.3 \mathrm{~mm}$ \\
\hline Circumferential segmentation pitch & $0.53 \mathrm{~mm}$ \\
\hline Average wall thickness & $0.50 \mathrm{~mm}$ \\
\hline Inside diameter & $14.1 \mathrm{~mm}$ \\
\hline Number of fins & $26 \mathrm{fpi}$ \\
\hline
\end{tabular}

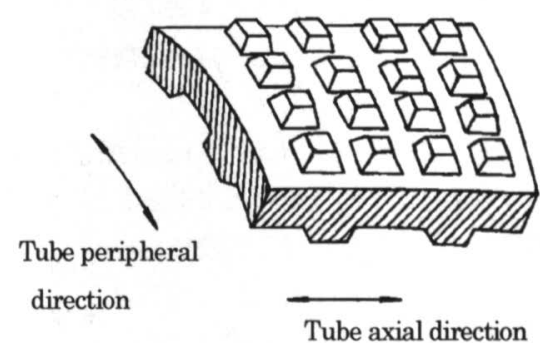

Fig.1 Image of test tube.



Fig.2 Cross-sectional view (Cut in longitudinal slice).

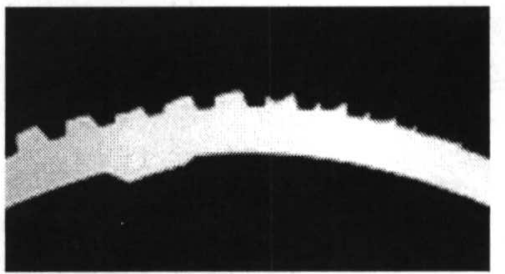

Fig.3 Cross-sectional view (Cut in round slice). 
を素材を使用し，転造加工にて製作した，独立㔖起型フィン は，管外面管長手方向インチあたり $26 \mathrm{fin}$ 相当の螦旋状のも のである。

\section{3. 試験装置及び撮影機器}

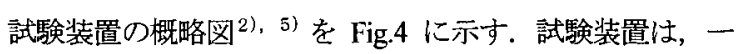
重効用の吸収式冷凍機と略同じサイクル構成となっており， 吸収器, 蒸発器, 再生器, 凝縮器及び水冷式の溶液熱交換器 にて構成されている. 試験装置本体の材質はSUS304 及び SUS316を採用している.

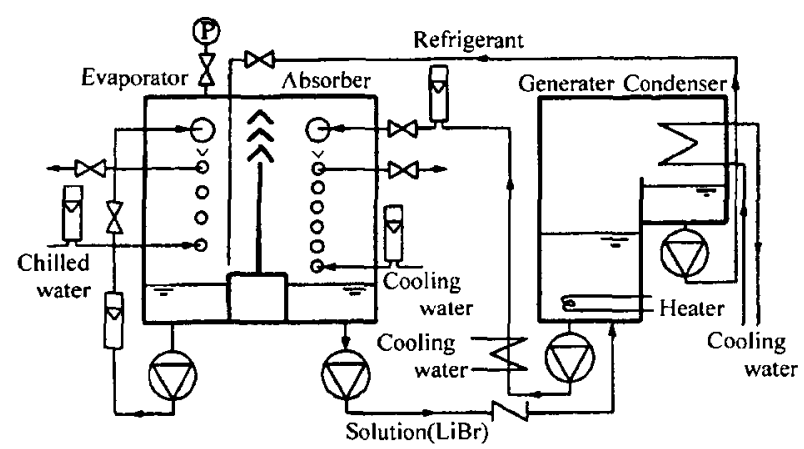

Fig.4 Schematic diagram of experimental set-up.

試験部となる, 蒸発部の概略を Fig.5 に示す。蒸発器は, 水平に伝熱管を設置し，管端部をOリングにてシールする構 造としている. また熱交換器の両側面は，冷媒及び吸収液の 流動が伝熱管の全面に渡って観察できるように厚さ $50 \mathrm{~mm} の$ アクリル製の観察用空を設けている。伝熱管の有効長は, $1050 \mathrm{~mm}$ であり, 蒸発器の管配列は 1 列 4 段の段ピッチ $24 \mathrm{~mm}$ で 4 本設置されている. 冷水渴度は一定の試験条件に調節さ れ，4 パスにて一定流量通水した。

冷媒の散布は滴下式を採用し, 滴下トレーは伝熱管最上段 の上方に設置し, 蒸発器下部に貯めた冷媒をポンプにてトレ 一に供給し，滴下ピッチ $10 \mathrm{~mm}$ にて試験した。

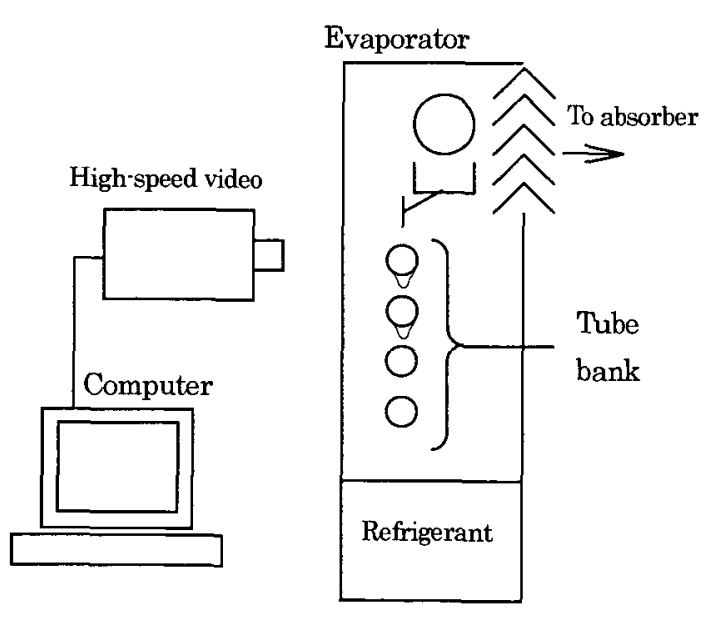

Fig.5 Schematic of test section.

流下液膜の流動撮影は, 最上段伝熱管を対象とし, 伝熱管
上部を撮影した，撮影機器は，高速度ビデオカメラ (PHOTRON, FASTCAM-PCI500, フレーム速度 500frames per second）を用いた. レンズはニコンの $35 \mathrm{~mm}$ レンズを使 用し，照明装置はメタルハライドライトにリングライトを使 用し, 撮影部分に照射した. 撮影画像は, 高速度ビデオ装置 の制御用コンピューター内のハードディスクに保存した。

\section{4. 評価及び撮影条件}

撮影は, 吸収式冷凍機の運転条件を考虑し, Table2 に示 す条件にて実施した. 評価は, 蒸発器の伝熱管に一定流量の 冷水を流し, 冷水出口温度が測定条件になるように泠水入口 水温を調節した. その後, 定常状態になったことを確認し, 撮影を実施した. なお，単位長さあたりの冷媒散布量は，管 両側を流れる冷媒量とし，(1)式にて定義した。

$$
\Gamma=\frac{G r e f}{60 \cdot L}
$$

ここで，「は単位長さ当たりの冷媒散布量 $[\mathrm{kg} /(\mathrm{min} \cdot \mathrm{m})]$, Gref は冷媒散布量 $[\mathrm{kg} / \mathrm{h}]$, L は伝熱有効長 $[\mathrm{m}]$ である.

Table 2 Test conditions

\begin{tabular}{l|l}
\hline Pressure in test chamber & $0.8 \mathrm{kPa}$ \\
\hline Refrigerant flow rate & $0.75 \sim 2.00 \mathrm{~kg} /(\mathrm{m} \mathrm{min})$ \\
\hline Chilled water velocity & $1.5 \mathrm{~m} / \mathrm{s}$ \\
\hline Temperature of outlet chilled water & $7.0^{\circ} \mathrm{C}$ \\
\hline Pieces of tube & $1 \mathrm{row} \times 4$ columns \\
\hline Number of passes & 4 \\
\hline Vertical tube pitch & $24 \mathrm{~mm}$ \\
\hline Pitch among refrigerant drop & $10 \mathrm{~mm}$ \\
\hline Tube length of the test section & $1050 \mathrm{~mm}$ \\
\hline Frame rate & $500 \mathrm{fps}$ \\
\hline Shutter Speed & $1 / 500 \mathrm{~s}$ \\
\hline Frame size & $512 \times 240$ \\
\hline
\end{tabular}

\section{5. 流動観察結果および考察}

高速度ビデオにて撮影した冷媒液膜流動を, Fig.6 8 に示 す。Fig.6 は冷媒散布量 $\Gamma=0.75 \mathrm{~kg} /(\mathrm{min} \cdot \mathrm{m}), F i g .7$ は $\Gamma=1.25 \mathrm{~kg} /(\mathrm{min} \cdot \mathrm{m})$, Fig. 8 は $\Gamma=2.00 \mathrm{~kg} /(\mathrm{min} \cdot \mathrm{m})$ のきの冷 媒液膜流動であり，各写真は $\mathrm{a}$ x の順番に $0.01 \mathrm{~s}$ 間隔にて示 した。また，Fig.6 8の a は泠媒が滴下され，伝熱管上部に 付着した時点に各々合わせた。

滴下されて伝熱管に冷媒が付着したあとの冷媒流動は, 突 起先端部にて液膜が厚く成形された後, 突起先端まで夜膜全 体が徐々に下がって薄膜化される傾向を示した。その後,

Fig.6 及び Fig.7 においては, 突起先端部を境に突起間满部 においてのみ液膜が下がり，次の液滴が付着する。

冷媒液滴の滴下は, 冷媒散布量が少なくなる程, 次の液滴 落下までの間隔が大きく, $\Gamma=0.75 \mathrm{~kg} /(\mathrm{min} \cdot \mathrm{m})$ では $0.23 \mathrm{~s}$ 以 内では滴下が無く， $\Gamma=1.25 \mathrm{~kg} /(\mathrm{min} \cdot \mathrm{m})$ では $0.23 \mathrm{~s}$ のとき (Fig.7のx), $\Gamma=2.00 \mathrm{~kg} /(\mathrm{min} \cdot \mathrm{m})$ では 0.16s のとき（Fig.8 の q) に散布される傾向を示した。散布間隔小さくなると， 管外表面の液膜は厚く残る㑯向にあり, Fig.6 及び Fig.7で 見られた突起間满部での液膜减少が見られない。 


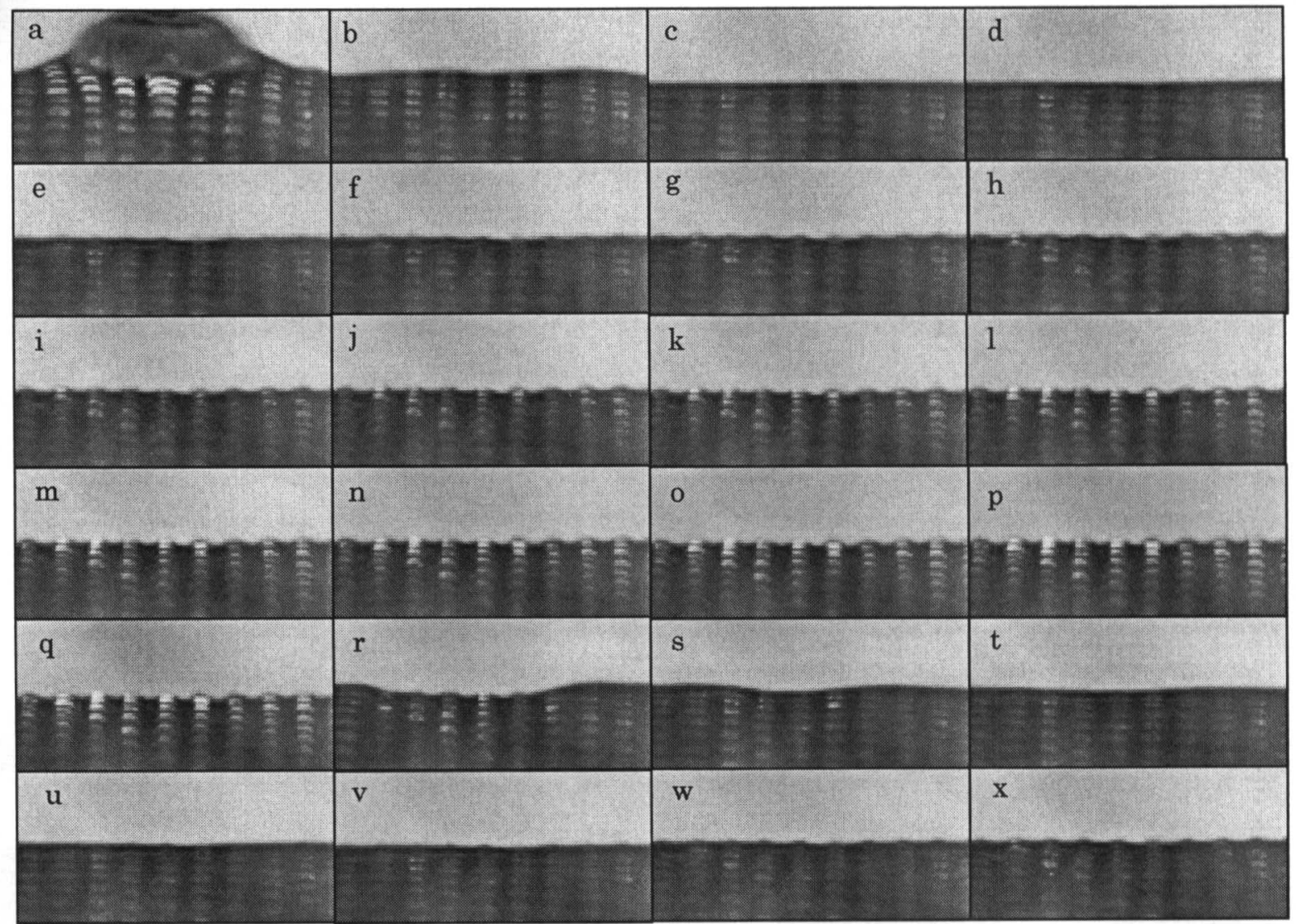

Fig.6 Refrigerant flow pattern: $\Gamma=0.75 \mathrm{~kg} /(\min \cdot \mathrm{m}) ; 0.01$ s time $\cdot$ steps

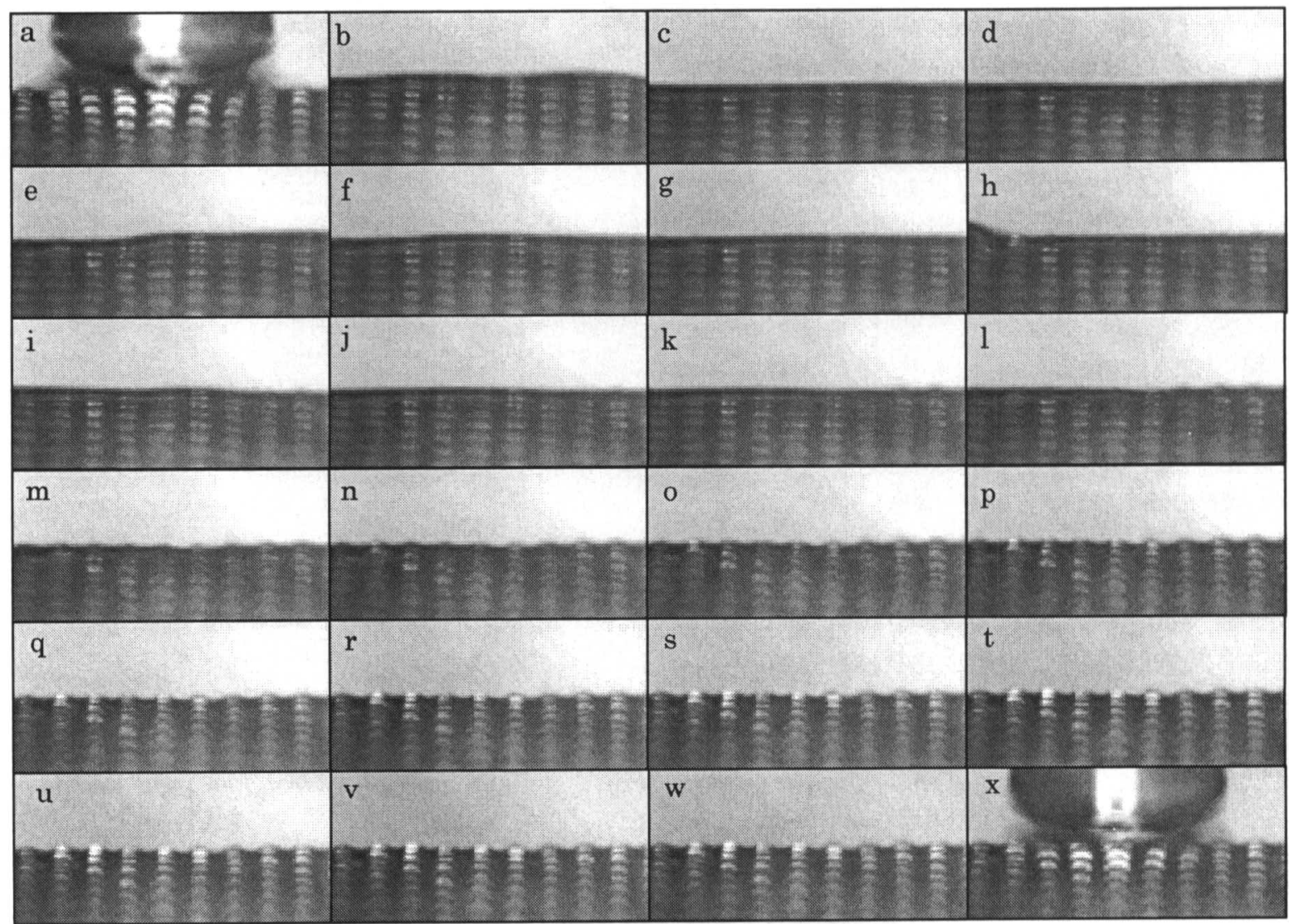

Fig.7 Refrigerant flow pattern $\Gamma=1.25 \mathrm{~kg} /(\min \cdot \mathrm{m}) ; 0.01 \mathrm{~s}$ time $•$ steps 


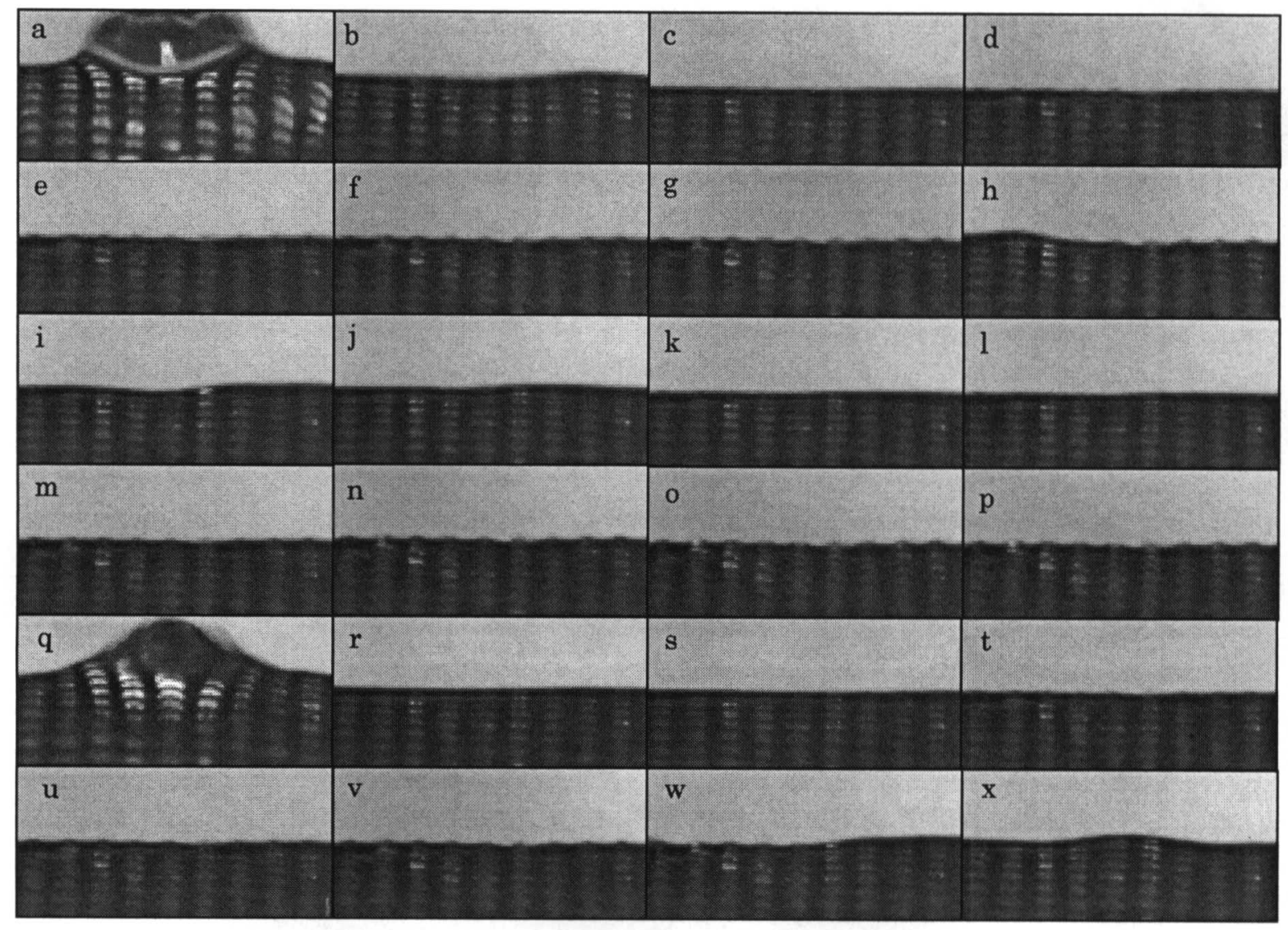

Fig.8 Refrigerant flow pattern: $\Gamma=2.00 \mathrm{~kg} /(\min \cdot \mathrm{m}) ; 0.01 \mathrm{~s} \mathrm{time-steps}$

一方，突起先端部に着目した結果， $\Gamma=0.75 \mathrm{~kg} /(\mathrm{min} \cdot \mathrm{m})$ の ときは Fig.6 の m q, $\Gamma=1.25 \mathrm{~kg} /(\mathrm{min} \cdot \mathrm{m})$ においては, Fig.7 の $\mathrm{q} \sim \mathrm{w}$ において突起先端部が明るくなる傾向を示した。こ れは突起先端部において液膜が薄くなっているともの考えら れる。小林ら ${ }^{4)}$ による VOF 解析も, 突起先端部での液膜薄 膜化ならびに蒸発が促進される結果が報告されており，この 撮影結果も同様の傾向を示している。

\section{6. 結 論}

流下液膜式蒸発器用として独立突起型伝熱管の泠媒液膜流 動を観察し、以下の結論を得た.

(1)冷媒液膜流動は, 冷媒が伝熱管付着後, 突起先端部にて 液膜が厚く成形された後, 突起先端まで液膜全体が徐々に下 がる傾向を示した。

(2)冷媒散布量が 0.75 ならびに $1.25 \mathrm{~kg} /(\mathrm{min} ・ \mathrm{~m})$ においては, 冷媒滴下間隔が大きくなり, 突起間溝部において液膜が下が り, 液膜が薄くなる傾向を示した。

（3）冷媒散布量が 0.75 ならびに $1.25 \mathrm{~kg} /(\mathrm{min} ・ \mathrm{~m})$ の撮影では, 突起先端部が明るくなる傾向を示し, 冷媒液膜が薄膜化され ることが示唆された。

\section{参 考 文 献}

1) 佐伯主税 : 特集 伝熱促進技術之熱交換器「1. 伝熱促進技術の研 究・開発動向」(1.4 各種伝熱管), 冷凍, Vol.75, No.874(2000) pp.21-24

2) 多田義男, 佐伯主税, 高橋宏行 : 独立突起を有寸る吸収式蒸発器 用伝熱管の伝熱特性，銅と銅合金，Vol.41(2002） pp.121-126.

3) Jesse D. Killion, Srinivas Garimella: Gravity-driven flow of liquid films and droplets in horizontal tube banks, International Journal of Refrigeration, Vol. 26, №. 5 (2003) pp. 516-526.

4) 小林利行, 高橋宏行, 佐伯主税: 吸収式冷温水機用伝熱管「工 ンドクロス」の蒸発過程における流動解析, 銅と銅合金, Vol.43(2004) pp.162-166.

5) 高橋宏行, 佐伯主税, 木島廣行 : 吸収式冷温水機の蒸発・吸収器 用伝熱管「エンドクロス」の伝熱特性, 伸銅技術研究会誌, Vol. 38(1999) pp. 263-267. 